\title{
How do urban slum women manage excessive vaginal discharge? A community based cross sectional study
}

IMPS llankoon ( $\sim$ prasanthi@sjp.ac.Ik )

University of Sri Jayewardenepura https://orcid.org/0000-0003-1393-1317

\section{CSE Goonewardena}

University of Sri Jayewardenepura Faculty of Medical Sciences

RC Fernandopulle

University of Sri Jayewardenepura Faculty of Medical Sciences

PPR Perera

University of Sri Jayewardenepura Faculty of Medical Sciences

Research article

Keywords: vaginal discharge; gynaecological complaint; health seeking behaviours; urban slum community

Posted Date: August 23rd, 2019

DOl: https://doi.org/10.21203/rs.2.13444/v1

License: (9) This work is licensed under a Creative Commons Attribution 4.0 International License. Read Full License 


\section{Abstract}

Background: Early detection of gnaecological morbidities is an important factor in treating and managing the underline disease. Abnormal vaginal discharge, which is a recurring problem for most of the women at reproductive age is a good predictor for many gynaeclogical morbidities. Many women constantly neglect abnormal vaginal discharge because of the prevailing "culture of silence". Women who live in urban slum are vulnerable for many unhealthy practices and lifestyles and having a high prevalence of reproductive tract infection especially sexually transmitted infections. Hence, this study was aimed to describe urban slum women' understanding, attitudes and related practices for abnormal vaginal discharge. Methods: This community based cross sectional study was conducted among 550 women living in urban slum in the Colombo Municipal Council area, Colombo District, Sri Lanka during September- March 2016. A multistage cluster sampling technique was used. A validated, pretested Interviewer Administered Questionnaire was used to collect information from females. Data were analysed using descriptive and relevant inferential statistics (Chi square test and one-way analysis of variance (ANOVA). Results: The majority of women (89.5\%) was unemployed and were married (92\%). The mean age of the women was 32.51 (SD \pm 7.94 ) years. Mean knowledge score was $29.18(\mathrm{SD} \pm 8.68)$. Most of the women $(97.1 \%)$ had inadequate level of knowledge $(<50 \%)$. A significant association was observed between the knowledge score levels with the participants' educational level $(p=0.00)$. Major areas of knowledge deficit include causes for pathological vaginal discharge and reproductive tract infections. Majority (95.9\%) agreed that abnormal vaginal discharge should be taken seriously but from the women who accepted (78.2\%) that vaginal discharge has ever been a concern to them, only $59 \%$ had consulted a general practitioner. There was a significant relationship with having accompanying symptoms such as burning sensation and lower abdominal pain and consulting a general practitioner $(p<0.05)$. Conclusion: The findings of the study imply the importance of health education to improve the health seeking behaviours. The culture specific health education intervention measures need to be targeted in order to improve their knowledge, attitudes and practices towards vaginal discharge as well as disease prevention and health promotion.

\section{Background}

Excessive vaginal discharge (leucorrhea) is a common distressing symptom for many women at reproductive age. It can be a symptom of vaginitis, and may be chronic or may recur after treatment ${ }^{1}$ and it is one of the most common health concerns presenting to the hospital ${ }^{2}$. Changes of hormonal levels during menstrual cycle, during pregnancy, due to sexual arousal and atrophic vaginitis are the physiological causes for excessive vaginal discharge ${ }^{3}$. The pathological causes includes infectious causes (Sexually Transmitted Infections (STIs) and Non-STIs) and non-infectious causes such as iatrogenic and malignancy (cervical cancer, endometrial cancer, vaginal cancer) ${ }^{4}$.

The most common vaginal infection among women of childbearing age is Bacterial vaginosis which is a non-STI ${ }^{5}$. Rather than the etiology or a definitive diagnosis, perceptions of the characteristics of the 
discharge and duration might make women concerned about their body image and decrease their selfesteem ${ }^{1}$. Women do not seek treatment as they find vaginal discharge as something shameful and uncomfortable to disclose and especially, women from South-East Asian region remain silent and thus go without treatment as they consider STIs as the cause of vaginal discharge ${ }^{6}$.

Urban poor are marginalized socially and economically due to structural and social inequalities, a brutal political economy, and neglect by policy makers ${ }^{7}$. The Colombo District in the western province of Sri Lanka extends over an area of 696 square kilometers with a population of 2,310,135 living in urban $(77.5 \%)$ rural $(22.2 \%)$ and estate $(0.4 \%)$ sectors of the District ${ }^{8}$. The metropolitan area of city of Colombo area is under the jurisdiction of Colombo Municipal Council (CMC) differs from the rest of the urban areas in respect to population density ${ }^{9}$. Two-thirds of Colombo city residents live in slum and shanties without basic amenities ${ }^{10}$.

The emerging issues among low income urban dwellers are lack of basic amenities, insecure income, family instability, drug addiction, domestic violence and a large number of school dropouts ${ }^{11}$. Further, socially marginalized communities have the highest rates of STIs and often do not have access to adequate health services ${ }^{12}$. Women live in urban slum communities are at risk of getting STIs and other reproductive tract infections due to their risk behaviours such as unsafe sex and prostitutions. Their knowledge and perceptions on different disease conditions and preventive strategies are important predictors to develop health promotion activities for this community. Therefore, this study was aimed to assess the knowledge, attitudes and different cultural practices associated with vaginal discharge and their associated factors among females living in urban slum communities in order to develop a culture specific health education intervention.

\section{Materials And Methods}

\section{Study Design}

This community based descriptive cross sectional study was conducted in a socially marginalized community in Colombo District, Sri Lanka from September- March 2016. The study population was females aged 18 - 49 years living in an urban slum for more than 6 months prior to the study. Females who were cognitively impaired at the time of the study were excluded.

\section{Sample Size and Sampling}

Sample size was calculated using $95 \%$ confidence level $(Z=1.96)$, the precision $(d)$ as 0.05 , design effect as 1.3. After inflate the sample size by another $10 \%$ to account for non-respondents, final sample size was 550 females. A multistage cluster sampling with stratification was used to identify the sample of 550 females. 
All the eligible slum wards (34) were selected for the study to achieve the sample size. Thereafter, 16 females aged 18-49 years (550/34) were selected from each slum ward until achieve the sample size. Starting point for sample collection in a cluster was the Community Center. After selecting the first house nearest to the Community Center, the subsequent house was selected the one which was closest to and to the right hand side of the first. From the selected houses, the female who is having closest birthday was selected to avoid taking all the females in the house. This procedure was continued until 16 eligible females were recruited from a cluster.

\section{Study instrument}

Data were collected using a validated, pretested Interviewer Administered Questionnaire. The judgmental validity of the questionnaire was carried out by group of experts in the field of reproductive health including experts from Dept. of Gynaecology and Obstetrics, Dept. of Community Medicine, National Institute of Health Sciences (NIHS) and Family Health Bureau in Sri Lanka. English version of the questionnaire were translated in to Sinhala and Tamil languages and again retranslated to English to ensure accuracy. Each correct answer was given a score of 1 and incorrect response 0 . The maximum score attainable was 25 . The total score was converted into percentage and knowledge was specified as Good level of knowledge- $>75 \%-100 \%$, Moderate level of knowledge - $50 \%-75 \%$, Poor / Inadequate level of knowledge $-<50 \%{ }^{13}$.

\section{Statistical analysis}

Data were coded and entered into Statistical Package for the Social Sciences (SPSS) software (version 20) before analysis. Descriptive statistics was applied to obtain percentages and means with standard deviation (SD) for the continuous variables. Chi square test was performed to assess the association between dependent and independent categorical variables. Pearson test was used when at least $80 \%$ of the cells have expected frequency of 5 or more in the contingency tables (two by two). If this assumption is violated Fisher's Exact test was used. Comparisons of mean knowledge score between three or more independent categorical variables were assessed using one-way analysis of variance (ANOVA) and posthoc comparisons were made using the Bonferroni procedure. A p value $<0.05$ was considered as statistically significant in all tests.

\section{Results}

\section{Socio-Demographic characteristics}

A total of 550 females participated in the study and the mean age of the subjects was 32.51 (SD 7.938) years. Nearly $38 \%(n=211)$ were Sinhalese and Buddhist. The mean duration of living in urban slum was 21.18 (SD 13.08) years. Two hundred thirty nine (43.5\%) participants had primary education level and 


\section{Score for overall knowledge related to vaginal discharge}

Mean knowledge score on vaginal discharge among study participants was 29.18 (SD 8.69). Majority of the study participants $(534,97.1 \%)$ had poor level of knowledge $(<50 \%)$ and a very few of the participants $(16,2.9 \%)$ had a moderate level of knowledge (50\%-75\%). There were no any participants having good level of knowledge ( $>75 \%)$ in the study sample. A significant association was observed between the knowledge score levels with the participants' educational level $(p=0.00)$. None of the other sociodemographic characteristics had significant associations with the knowledge score levels.

The median knowledge score declined significantly in lower educational levels when compared to higher level of education. There was a statistically significant difference in median differences of knowledge score across all four educational groups $(H=26.99, p=0.00)$ with a mean rank of 259.70 for not attended school, 243.88 for primary education, 288.44 for Ordinary Level and 346.69 for Advanced level group respectively. Post- hoc test (Mann-Whitney $U$ test) comparisons of four groups indicate that median knowledge score was significantly higher among participants who had educated up to Advanced Level when compared to not attended school $(p=0.03)$, Primary Education $(p=0.00)$, and Ordinary Level $(p=$ 0.002).

\section{Knowledge related to vaginal discharge}

About $70 \%$ of the study participants $(n=386)$ were of the opinion that vaginal discharge is always normal. Most of them (81\%) were of the opinion that the color of the vaginal discharge is white. The consistency of the normal vaginal secretion was identified as thin by $55.8 \%$ and mucoid by $26.9 \%$. Majority (91\%) agreed that the odor of the normal vaginal secretion is non-offensive.

As shown in table 2, majority of the study participants (83.5\%) were of the opinion that "a clear, nonoffensive discharge that varies with the menstrual cycle is a normal physiological secretion", "vaginal secretions vary with menstrual cycle" (73.3\%), "women aged between 15-49 years have a normal physiological vaginal secretion" (85.1\%,), and "white or colored vaginal discharge may be a sign of reproductive tract infections" (66\%).

\section{Knowledge related to causes for excessive vaginal discharge}


The main causes for excessive vaginal discharge identified by the participants were high body temperature (82.2\%) and vitamin deficiency (55.6\%). Nearly half of the participants identified Human Immunodeficiency Virus (HIV) as a STI (59.5\%). Most of the participants (62.0\%) stated that they receive information on vaginal discharge from their relatives.

\section{Attitudes towards vaginal discharge}

The majority of the study participants (96\%) agreed that abnormal vaginal discharge should be taken seriously and $93 \%$ agreed that, it is necessary to take treatment for offensive vaginal discharge. The majority agreed excessive vaginal discharge can occur due to "body heat" (85.1\%), due to "body weakness" (84.2\%) and due to "vitamin deficiency" (65.6\%). In addition, more than half of the study participants $(59.6 \%)$ agreed that it is uncomfortable to talk about vaginal discharge with others (Table 4).

\section{Experience with vaginal discharge and Health seeking behaviours}

Majority of the participants ( $n=430,78.2 \%)$ stated that vaginal discharge has ever been a concern to them. Among them, more than $60 \%$ mentioned that itchiness and scratching is a common accompanying symptom. Nearly $59 \%$ of them had consulted a general practitioner. More than half of the participants have used Fenugreek (Uluhal) drink (62.6\%) and polpala herbal drink (57\%) as home remedies for excessive vaginal discharge (Table 5). There was a significant association between the employment status with the health seeking behaviours from a General Practitioner in the present study (Pearson Chi Square, $p<0.05)$.

There was a statistically significant association between seeking treatment from a general practitioner and experiencing accompanying symptoms such as lower abdominal pain $(p=0.01)$, and burning sensation $(p=0.00)$ (Table 6).

\section{Perceived factors associated with health seeking behaviours towards excessive vaginal discharge}

The perceived factors associated with females' decision on self-treatment for excessive vaginal discharge were identified as embarrassment in discussing with doctors (54\%) and cultural view of vaginal discharge (36.7\%). Majority (87.5\%) mentioned that feeling difficulty in discussing with a male doctor and less knowledgeable about vaginal discharge $(61.1 \%)$ as the reasons for them not to take medical advice for excessive vaginal discharge.

\section{Discussion}


Vaginal discharge is a major health concern among women of reproductive age group. The findings of this study provide insights into the current level of understanding about vaginal discharge and different practices among females aged 18 to 49 years living in an urban slum community.

This study revealed that majority of the participants had a previous history of abnormal vaginal discharge in their lifetime. This is comparable to a similar study conducted in New York City which showed that $85 \%$ of women presented with itching and vaginal discharge ${ }^{14}$. Another study conducted among women aged 18-60 years in South Africa have found that almost half of the participants reported having an abnormal discharge at least once $(47.1 \%)^{15}$. Further, nearly half of the married adolescent women have experienced white vaginal discharge in a Dhaka urban slum community ${ }^{7}$.

The knowledge level of the females of urban slum community on different aspects of vaginal discharge was found to be inadequate; the mean knowledge score on vaginal discharge among females in the urban slum community was 29.18 (SD 8.69) out of 100 . Similarly, a study conducted among married women who were suffering from vaginal discharge in Pakistan revealed that most of the females had no prior factual knowledge about vulvo-vaginal discharge and its nature ${ }^{16}$. There has been a statistically significant difference in knowledge score noticed with respect to the highest educational level in the urban slum community. In another study, a significant association between educational status of the female and consultation for vaginal discharge has been observed in a study conducted to assess rural women's perception and health care seeking behaviour regarding excessive vaginal discharge in India ${ }^{17}$. Similarly, poor level of knowledge related to vulvo-vaginal discharge was found among women having low educational level in a similar study conducted among women living in estate sector, Sri Lanka ${ }^{18}$. The poor knowledge on vulvo-vaginal discharge and reproductive tract infections among the females in the present study might be related to their educational levels which keep them away from learning new things.

Similar to other studies done in Asian countries, majority of females in the present study displayed poor knowledge on reproductive tract infections, including both STIs and non-STIs ${ }^{19,20}$. Another study, brought up the idea that the overall knowledge of the respondents about the symptoms of reproductive tract infections was poor, and only nearly half agreed that vaginal discharge is a symptom of reproductive tract infections ${ }^{21}$. In the present study, majority of the females were not aware of the causes for excessive vaginal discharge such as infections including STIs, and cancer but expressed that the excessive vaginal discharge is due to high body temperature, vitamin deficiencies and consumptions of heaty food. Similar to that, women has shown lack of knowledge on vaginal discharge and its causes in another study 22 . Further, similar to the present study findings, heaty food and excessive body heat were recognized as causes for excessive vaginal discharge by the respondent in another study ${ }^{17}$ (Mammen, et al., 2017). Furthermore, some studies have recognized that using antibiotics, contraceptive pills, washing powder or products used in the bath, overheating or tight trousers and sterilization operation and sexually transmitted disease as causes for excessive vaginal discharge ${ }^{23}$. 
Misconceptions on causes of abnormal vaginal discharge, which can lead to certain practices such as use of home remedies and Ayurvedic treatment, were revealed in this study. Similar to the present study, a study conducted in rural communities in India identified lack of awareness regarding causes of abnormal vaginal discharge ${ }^{17}$. Women have mentioned that poverty/ tension/ worries and weakness as possible causes of vaginal discharge in studies conducted in Nepal and Bangladesh ${ }^{6,7}$.

Majority of the females in the present study had the attitude of any type of vaginal discharge is a normal condition and it prevents them from seeking medical advice even for pathological vaginal discharge. In contrast, in a study conducted in Katmandu, Nepal, more than half (51\%) of the women believed that vaginal discharge was not a normal condition ${ }^{6}$. Although the majority agreed that treatment is necessary for offensive vaginal discharge, it was found in the present study that nearly $59 \%$ of women in urban slum community had consulted a general practitioner and sought medical advice. In contrast, a study conducted among women of reproductive age in Lagos, Nigeria highlights that, vaginal discharge was one of the commonest symptom reported $(21.8 \%)$ and majority of the women $(87.9 \%)$ have sought medical advice for abnormal vaginal discharge ${ }^{21}$. It has been explained that high prevalence of treatment seeking is due to the awareness about infertility as a complication of STIs and of the need to prevent it ${ }^{21}$.

In the present study, majority have mentioned that it is difficult to discuss about vaginal discharge with male doctors similar to other studies ${ }^{24}$. Another study highlights that women were found hiding vaginal discharge due to embarrassment, shyness and environmental constraints ${ }^{16}$. Further, it has been found that women believe that vaginal discharge is a result of a woman's fate and that it is unexplainable ${ }^{25}$. Furthermore, following several treatment modalities that were unsuccessful, women have been observed concluding that vaginal discharges is incurable, and they must learn to live with $\mathrm{it}^{26}$. Therefore, proper education on vaginal discharge and related health conditions need to be given to the females in order to recognize abnormal vaginal discharge.

The present study discovered that many women preferred self-treatment and homeopathic care for abnormal vaginal discharge, as they were affordable, and some of them said that they visited local pharmacies and healers to manage the symptoms. Furthermore, another study by O'dowd, Parker and Kelly (1996), found that one-third of women used over-the-counter remedies, mostly even without consulting the pharmacist ${ }^{24}$. The most commonly used home remedies for abnormal vaginal discharge among urban slum community were Uluhal (Fenugreek) drink and Polpala herbal drink (Balipoovu, Aerva lanata). Some South Asian Ayurveda practitioners have advised women to avoid 'heaty' food such as ghee, eggs or meat, to prevent of vaginal discharge ${ }^{2}$.

In addition, cultural views on vaginal discharge was mentioned by a few females as a reason for not seeking medical advice in the present study. Majority of the females in the present study mentioned that they have sought treatment at the end, because the condition got worse or due to fear of serious disease consequences or due to vaginal discharge being intolerable. Rashid (2007) found that women seek treatment from doctors only when the discharge became "abnormal," "smelly," or "thick"7. 
In a study conducted among women living in low socio-economical status in India has found that the majority of the women with vaginal discharge had another coexisting gynaecological complaint $(94 \%)^{27}$. The researchers have found that there is a strong association between the coexisting gynaecological complaint and vaginal discharge ${ }^{27}$. Similar to that, in the present study found that, having other accompanying symptoms with vaginal discharge, such as lower abdominal pain and burning sensation, were considered positive predictors to seek medical advice similar to other studies ${ }^{18,21,28}$.

\section{Conclusions}

Study participants demonstrated poor understanding of different aspects of abnormal vaginal discharge. Women try to hide abnormal vaginal discharges due to poor knowledge and being afraid of disclosing such matters due to social taboo attached to them. This leads to serious consequences of untreated reproductive morbidities. Adequate information is needed to be given to women regarding the normal and abnormal vaginal discharge, which will help them to get early treatments for pathological vaginal discharge. It is necessary to organize health education programmes for the given community, making these factors the fundamental consideration.

\section{Implications of this study}

Topics such as recognition of abnormal vaginal discharge, common causes for vaginal discharge (including STIs, Non-STIs and malignancy) and consequences of untreated abnormal vaginal discharge can be included in to a culture specific health education programme for this community. Further it is necessary to address their different cultural practices and beliefs regarding vaginal discharge during the educational programme. This would help women to identify abnormal vaginal discharge which leads to improve health seeking behaviours towards pathological vaginal discharge. Further, it is essential to provide a comfortable and confidential environment for women to discuss the problem in privacy. It enhances the health seeking behavior of women for abnormal vaginal discharges.

\section{List Of Abbreviations}

CMC- Colombo Municipal Council

HIV- Human Immunodeficiency Virus

ANOVA- one-way analysis of variance

NIHS- National Institute of Health Sciences

STIs- Sexually Transmitted Infections

SD-Standard Deviation 
VD - Vaginal Discharge

\section{Declarations}

\section{Acknowledgements}

The authors thank all the participants, Public Health Midwives and the staff in the Maternal and Child Welfare Centers, $\mathrm{CMC}$ for their support.

\section{Funding}

This research was supported by the institutional research grant (Grant No: ASP/06/RE/MED/2013/31) of University of Sri Jayewardenepura, Sri Lanka.

\section{Authors' contributions}

IMPS, CSE, RC, and PPR have been responsible for the idea and the design of the study. IMPS drafted the manuscript and performed the analyses. All authors revised the manuscript and had critical discussions of the manuscript. All authors have approved the final version of the manuscript.

\section{Ethics approval and consent to participate}

Ethical clearance was obtained from the Ethics Review Committee, Faculty of Medical Sciences, University of Sri Jayewardenepura, Sri Lanka (ERC Ref: No: 27/14). The procedures followed were in accordance with the ethical standards of the Declaration of Helsinki of the World Medical Association. All participants gave written informed consent before commencement of the data collection.

\section{Consent for publication}

Not applicable

\section{Competing interests}

Authors declare that there is no conflict of interest. 


\section{Availability of data and materials}

The datasets used and/or analysed during the current study are available from the corresponding author on reasonable request.

\section{References}

1. Gungor, A. N. C., Uludag, A., Sahin, M., Gencer, M., Uysal, A. 2014. Effects of vaginal discharge on female sexual function. International journal of gynaecology and obstetrics: the official organ of the International Federation of Gynaecology and Obstetrics. 124(1); 27-9.

2. Trollope-Kumar, K., 2001. Cultural and biomedical meanings of the complaint of leukorrhea in South Asian women. Tropical Medicine \& International Health, 6(4), pp. 260-266.

3. Campbell S and Monga A. Gynaecology by Ten Teachers. 2000. 17th ed. Gutenberg Press LtD.

4. Bates, S. 2003. Vaginal discharge. Current Obstetrics \& Gynaecology.13 (4): 218-223.

5. Turovskiy, Y., Sutyak, N, K., and Chikindas, M. L. 2011. The aetiology of bacterial vaginosis. Journal of Applied Microbiology. 110(5); 1105-28.

6. Rizvi, N. and Luby, S., 2004. Vaginal Discharge: Perceptions and health seeking behaviours among Nepalese Women. Journal of Pakistan Medical Association, 54(12), pp. 620-624.

7. Rashid, S. F., 2007. Durbolota ( Weakness), Chinta Rog (Worry Illness), and Poverty. Medical Anthropology Quarterly, 21(1), pp.108-132.

8. Department of Census and Statistics, 2012. Census of Population and Housing 2012. Sri Lanka. [online] Available at: http://www.statistics.gov.lk/PopHouSat/CPH2011/ Pages/Activities/Reports/CPH_2012_5Per_Rpt.pdf [Accessed 28 August 2016].

9. Van Horen B. City Profile: Colombo, cities 2002; 19(03); 217-27.

10. UNHABITAT, 2007. United Nations Human Settlement Profile, Sri Lanka, District Housing Programm, Colombo District. The United Nations Human Settlements Programme. [online] Available at: http://unhabitat.Ik/, [Accessed 13 May 2016].

11. Niriella, N. C., 2010. Critical Issues of Low-Income Dwellers in Urban Planning. Conference paper. [online] Available at: https://www.researchgate.net/ publication/320841463_CRITICAL_ISSUES_OF_LOW-INCOME_DWELLERS_IN_URBAN_PLANNING, [Accessed 01 Decemeber 2017].

12. D'Souza, M. S., Somayaji, G. and Subrahmanya, N. K., 2011. Determinants of reproductive health and related quality of life among Indian women in mining communities. Journal of Advanced Nursing, 67(9), pp.1963-1975.

13. Zaher, E. H., Khedr, N. F. H. and Elmashad, H. A.M., 2017. Awareness of Women Regarding Vaginal Discharge. IOSR Journal of Nursing and Health Science, 6(1), pp.1-12.

14. Karasz, A. and Anderson, M., 2003. The vaginitis monologues: Women's experiences of vaginal complaints in a primary care setting. Social Science and Medicine, 56, pp.1013-1021. 
15. Smit, J., Chersich, M. F., Beksinska, M., Kunene, B., Manzini, N., Hilber, A.M. and Scorgie, F., 2011. Prevalence and self-reported health consequences of vaginal practices in KwaZulu-Natal, South Africa: findings from a household survey. Tropical Medicine \& International Health, 16(2), pp.245256.

16. Fatima, $\mathrm{H}$. and Khan, N, 2013. Perceptions of women reporting vaginal discharge at gynecology clinics in lahore. Journal of Behavioural Sciences. 23(3): 21-34.

17. Mammen, S. A., Singh, S., Rajesh, I. and Goyal, S., 2017. Perception and correlates of excessive vaginal discharge in rural women. International Journal of Reproduction, Contraception, Obstetrics and Gynecology, 6(8), pp.3502-3506.

18. Ilankoon, I. M. P. S., Goonewardena, C. S. E., Fernandopulle, R. C. and Perera, P. P. R., 2017. Women's knowledge and experience of abnormal vaginal discharge living in estates in Colombo District, Sri Lanka. International Journal of Women's Health and Reproduction Sciences, 5(2), pp. 90-96. DOI: 10.15296/ijwhr.2017.17

19. Onal, A. E., Onoglu, N., Babaoglu, A. B., Ozer, C. and Gungor, G., 2011. Some Hygiene Behaviours and Genital Infection Complaints among 15-49 aged Women in a Suburban Area of Istanbul. Nobel Medicine, 7, pp. 96-100.

20. Nielsen, A., Lan, P. T., Marrone, G., Phuc, H. D., Chuc, N. T. K. and Lundborg, S. C., 2014. Reproductive Tract Infections in Rural Vietnam, Women's Knowledge, and Health-Seeking Behavior: A CrossSectional Study. Health care for women international, 37(4), pp.392-411.

21. Rabiu, K., Adewunmi, A., Akinlusi, F. M. and Akinola, O.I, 2010. Female reproductive tract infections: understandings and care seeking behaviour among women of reproductive age in Lagos, Nigeria. BMC women's health, 10; 8.

22. Rakhmilla, L. E., Ilona, L., Sofiatin, Y., Widjadjakusuma, A. and Rosyada, N. A., 2016. Knowledge, Attitude, and Practice about Vaginal Discharge on School-Age Girls in Jatinangor Senior High School. Open Access Library Journal, 3: e3130. Doi: org/10.4236/oalib.1103130.

23. Chapple, A., 2001. Vaginal thrush: perception and experiences of women of South Asian descent. Health Education Research, 16(1), pp.9-19.

24. O'dowd, T. C., Parker, S. and Kelly, A., 1996. Women's experiences of general practitioner management of their vaginal symptoms. British Journal of General Practice, 46, pp.415-418.

25. Kulkarni, R. and Chauhan, S., 2009. Socio-Cultural Aspects of Reproductive Morbidities among Rural Women in a District of Maharashtra, India. The Journal of Family Welfare, 55 (2), pp.27-33.

26. Ross, J. L., Laston, S. L., Pelto, P. J. and Muna, L., 2002. Exploring explanatory models of women's reproductive health in rural Bangladesh. Culture, Health and Sexuality, 4(2), pp. 173-190.

27. Chaudhary, V., Kumar, R., Agrawal, V. K., Singh, A., Narula, R. and Sharma, M., 2012. Prevalence and Determinants of Vaginal Discharge among women of reproductive age group in tertiary care hospital of Northern. National Journal of Community Medicine, 3 (4), pp. 661-665.

28. Gulati, S. C., Chaurasia, A. R. and Singh, R. M., 2009. Women's Reproductive Morbidity and TreatmentSeeking Behaviour in India. Asian Population Studies, 5(1), pp.61-84. 


\section{Tables}

Table 1: Knowledge score levels and other socio-demographic characteristics $(n=550)$

\begin{tabular}{|c|c|c|c|c|}
\hline \multicolumn{2}{|c|}{ Characteristics } & \multicolumn{2}{|c|}{ Knowledge score levels } & \multirow[t]{2}{*}{$\mathrm{p}$ value } \\
\hline & & Poor n (\%) & Moderate $\mathrm{n}(\%)$ & \\
\hline \multirow[t]{3}{*}{ Ethnicity } & Sinhala & $201(37.6)$ & $10(62.5)$ & $0.10^{\#}$ \\
\hline & Muslim & $175(32.8)$ & $2(12.5)$ & \\
\hline & Tamil & $158(29.6)$ & $4(25.0)$ & \\
\hline \multirow[t]{4}{*}{ Religion } & Buddhist & $200(37.5)$ & $8(50.0)$ & $0.17^{\$}$ \\
\hline & Islam & $157(29.4)$ & $2(12.5)$ & \\
\hline & Hindu & $115(21.5)$ & $2(12.5)$ & \\
\hline & Christian & $62(11.6)$ & $4(25.0)$ & \\
\hline \multirow[t]{3}{*}{ Age categories } & 18-25 years & $120(22.5)$ & $2(12.5)$ & $0.42^{\#}$ \\
\hline & 26-35 years & $217(40.6)$ & $9(56.3)$ & \\
\hline & $36-49$ years & 197 (36.9) & $5(31.2)$ & \\
\hline \multirow[t]{4}{*}{ Highest educational level } & Not attended school & $20 \quad(3.7)$ & $0 \quad(0.0)$ & $0.00^{\$}$ \\
\hline & Primary Education & $236(44.2)$ & $03(18.8)$ & \\
\hline & Ordinary Level & 215 (40.3) & $03(18.8)$ & \\
\hline & Advance Level & $63(11.8)$ & $10(62.4)$ & \\
\hline \multirow[t]{2}{*}{ Employment status } & Employed & $56(10.5)$ & $2(12.5)$ & $0.68^{£}$ \\
\hline & Unemployed & $478(89.5)$ & $14(87.5)$ & \\
\hline \multirow[t]{3}{*}{ Employment category } & Unemployed & 478 (89.5) & $14(87.5)$ & $0.63^{\$}$ \\
\hline & Government job & $11(2.1)$ & $0 \quad(0.0)$ & \\
\hline & Non-government job & $45(8.4)$ & $2(12.5)$ & \\
\hline \multirow[t]{3}{*}{ Marital Status } & Married & 490 (91.8) & $16(100.0)$ & $0.26^{\$}$ \\
\hline & Single & $37(6.9)$ & $0 \quad(0.0)$ & \\
\hline & Separated/widow & $7(1.3)$ & $0 \quad(0.0)$ & \\
\hline \multirow[t]{3}{*}{ Family type } & Nuclear & 240 (44.9) & $6(37.5)$ & $0.52^{\#}$ \\
\hline & Extended & $194(36.4)$ & $8(50.0)$ & \\
\hline & Joint & $100(18.7)$ & $2(12.5)$ & \\
\hline
\end{tabular}

\# - Pearson chi-square, \$ - Likelihood ratio, £- Fisher's Exact test

Table 2: Knowledge related to vaginal discharge among urban slum community $(n=550)$ 


\begin{tabular}{|c|c|c|c|}
\hline Responses & $\begin{array}{r}\text { True } \\
\mathrm{n}(\%)\end{array}$ & $\begin{array}{l}\text { False } \\
\mathrm{n}(\%)\end{array}$ & $\begin{array}{l}\text { Don't } \\
\text { Know } \\
\text { n (\%) }\end{array}$ \\
\hline $\begin{array}{l}\text { A clear, non-offensive discharge that varies with the menstrual cycle is a normal } \\
\text { physiological secretion. }\end{array}$ & $\begin{array}{r}459 \\
(83.5)\end{array}$ & $\begin{array}{r}44 \\
(8.0)\end{array}$ & $47(8.5)$ \\
\hline Vaginal secretions vary with menstrual cycle. & $\begin{array}{r}403 \\
(73.3)\end{array}$ & $\begin{array}{c}31 \\
(5.6)\end{array}$ & $\begin{array}{r}116 \\
(21.1)\end{array}$ \\
\hline The most common cause of vaginal discharge is STIs. & $\begin{array}{c}31 \\
(5.6)\end{array}$ & $\begin{array}{r}87 \\
(15.8)\end{array}$ & $\begin{array}{r}432 \\
(78.4)\end{array}$ \\
\hline Women aged between 15-49 years have a normal physiological VD & $\begin{array}{r}468 \\
(85.1)\end{array}$ & $\begin{array}{c}19 \\
(3.5)\end{array}$ & $\begin{array}{r}63 \\
(11.4)\end{array}$ \\
\hline White or colored VD may be a sign of reproductive tract infections. & $\begin{array}{r}363 \\
(66.0)\end{array}$ & $\begin{array}{r}12 \\
(2.2)\end{array}$ & $\begin{array}{r}175 \\
(31.8)\end{array}$ \\
\hline Candida infection is a sexually transmitted infection. & $\begin{array}{r}15 \\
(2.7)\end{array}$ & $\begin{array}{r}43 \\
(7.8)\end{array}$ & $\begin{array}{r}492 \\
(89.5)\end{array}$ \\
\hline
\end{tabular}

VD - vaginal discharge

Table 3: Awareness of causes of excessive vaginal discharge and STIs $(n=550)$ 


\begin{tabular}{lr}
\hline Responses & $\mathbf{n}(\%)$ \\
\hline Causes stated by participants for excessive vaginal discharge ${ }^{\mu}$ & \\
High body temperature & $452(82.2)$ \\
Vitamin deficiency & $306(55.6)$ \\
Heaty food & $127(23.1)$ \\
Infections & $118(21.5)$ \\
Pregnancy & $65(11.8)$ \\
Body weakness & $61(11.1)$ \\
Poor personal hygiene & $39(7.1)$ \\
Bone melting & $35(6.4)$ \\
Stress & $34(6.2)$ \\
Sexually transmitted Infections & $28(5.1)$ \\
Family planning methods & $18(3.3)$ \\
Melting veins & $8(1.5)$ \\
Awareness of sexually transmitted infection ${ }^{\mu}$ & \\
HIV/AIDS & $327(59.5)$ \\
Gonorrhoea & $20(3.6)$ \\
Herpes & $8(1.5)$ \\
Syphilis & $7(1.3)$ \\
Genital warts & $7(1.3)$ \\
\hline
\end{tabular}

${ }^{\mu}$ Multiple responses were allotted.

Table 4: Attitudes regarding vaginal discharge $(n=550)$ 


\begin{tabular}{|c|c|c|c|}
\hline Statements indicating positive attitudes & $\begin{array}{l}\text { Agree } \\
\mathrm{n}(\%)\end{array}$ & $\begin{array}{l}\text { Don't Know n } \\
\text { (\%) }\end{array}$ & $\begin{array}{l}\text { Disagree } \mathrm{n} \\
(\%)\end{array}$ \\
\hline Abnormal vaginal discharges should be taken seriously. & $\begin{array}{r}527 \\
(95.9)\end{array}$ & $14(2.5)$ & $9(1.6)$ \\
\hline It is necessary to take treatment for offensive vaginal discharge. & $\begin{array}{r}509 \\
(92.5)\end{array}$ & $23(4.2)$ & $18(3.3)$ \\
\hline Statements indicating negative attitudes & $\begin{array}{l}\text { Agree } \\
\text { n (\%) }\end{array}$ & $\begin{array}{r}\text { Don't Know } \\
\text { n (\%) }\end{array}$ & $\begin{array}{r}\text { Disagree } n \\
(\%)\end{array}$ \\
\hline Excessive vaginal discharge can occur due to body heat. & $\begin{array}{r}468 \\
(85.0)\end{array}$ & $52(9.5)$ & $30(5.5)$ \\
\hline Excessive vaginal discharge can occur due to body weakness. & $\begin{array}{r}463 \\
(84.2)\end{array}$ & $58(10.5)$ & $29(5.3)$ \\
\hline Any type of vaginal discharge is a normal condition. & $\begin{array}{r}454 \\
(82.6)\end{array}$ & $25(4.5)$ & $71(12.9)$ \\
\hline Excessive vaginal discharge can occur due to vitamin deficiency. & $\begin{array}{r}361 \\
(65.6)\end{array}$ & $141(25.6)$ & $48(8.8)$ \\
\hline Those who have excessive vaginal discharge are not healthy. & $\begin{array}{r}331 \\
(60.2)\end{array}$ & $75(13.6)$ & $144(26.2)$ \\
\hline I find it uncomfortable to talk about vaginal discharge. & $\begin{array}{r}328 \\
(59.6)\end{array}$ & $21(3.8)$ & $201(36.6)$ \\
\hline $\begin{array}{l}\text { Those who have excessive vaginal discharge don't have good } \\
\text { personal hygiene. }\end{array}$ & $\begin{array}{r}305 \\
(55.5)\end{array}$ & $85(15.5)$ & $160(29.0)$ \\
\hline $\begin{array}{l}\text { No need to take treatment for excessive VD as it is due to eating } \\
\text { heaty food. }\end{array}$ & $\begin{array}{r}94 \\
(17.1)\end{array}$ & $308(56.0)$ & $148(26.9)$ \\
\hline Excessive vaginal discharge can occur due to bone melting. & $\begin{array}{r}77 \\
(14.0) \\
\end{array}$ & $389(70.7)$ & $84(15.3)$ \\
\hline
\end{tabular}

Table 5: common symptoms, practices and health seeking behaviours related to abnormal vaginal discharge $(\mathrm{n}=$ 430) 


\begin{tabular}{lr}
\hline Responses & (n, \%) \\
\hline Common symptoms associated with abnormal vaginal discharge \\
\hline Itchiness and scratching & $266(61.9)$ \\
Lower abdominal pain & $140(32.6)$ \\
Burning sensation & $74(17.2)$ \\
Pain at intercourse & $23 \quad(4.4)$ \\
& \\
Health seeking behaviours for abnormal vaginal discharge & \\
& \\
Consulted a general practitioner & $175(59.3)$ \\
Discuss with friend or relatives & $96(22.3)$ \\
Used Home Remedies & $24 \quad(5.6)$ \\
Discuss with Public Health Midwives & $21 \quad(4.9)$ \\
Consulted Ayurvedic Doctor & $15 \quad(3.5)$ \\
Use over the counter drugs & $9(2.1)$ \\
& \\
Home remedies used for abnormal vaginal discharge & \\
& \\
Fenugreek (Uluhal) drink & $269(62.6)$ \\
Polpala herbal drink & $245(57.0)$ \\
Sago (Sauw) Kanji & $161(37.4)$ \\
Drink king coconut & $133(30.9)$ \\
Boiled cumin (Suduru) drink & $46(10.7)$ \\
\hline
\end{tabular}

${ }^{\mu}$ Multiple responses were allotted.

Table 6: Accompanying symptoms experienced with abnormal vaginal discharge and consultation with General Practitioner $(n=430)$

\begin{tabular}{|c|c|c|c|c|}
\hline \multirow{2}{*}{\multicolumn{2}{|c|}{ Accompanying symptoms }} & \multicolumn{2}{|c|}{ Consulted a General Practitioner } & \multirow[t]{2}{*}{$\mathrm{p}$ value $\#$} \\
\hline & & Yes (n, \%) & No $(n, \%)$ & \\
\hline \multirow[t]{2}{*}{ Itchiness and scratching } & Yes & $116(66.3)$ & $150(58.8)$ & 0.12 \\
\hline & No & $59(33.7)$ & $105(41.2)$ & \\
\hline \multirow[t]{2}{*}{ Lower abdominal pain } & Yes & $69(39.4)$ & $71(27.8)$ & 0.01 \\
\hline & No & $106(60.6)$ & $184(72.2)$ & \\
\hline \multirow[t]{2}{*}{ Burning sensation } & Yes & $42(24.0)$ & $32(12.5)$ & 0.00 \\
\hline & No & $133(76.0)$ & $223(87.5)$ & \\
\hline \multirow[t]{2}{*}{ Pain during intercourse } & Yes & $9 \quad(5.1)$ & $14 \quad(5.5)$ & 0.87 \\
\hline & No & 166 (94.9) & $241(94.5)$ & \\
\hline
\end{tabular}


\# - Pearson chi-square

Table 7: Perceived factors associated with health seeking behaviours towards excessive vaginal discharge

\begin{tabular}{|c|c|}
\hline Responses & $\mathrm{n}(\%)$ \\
\hline \multicolumn{2}{|l|}{ Factors associated with females' decision on self-treatment } \\
\hline Embarrassment in discussing with doctors & $297(54.0)$ \\
\hline Cultural view of vaginal discharge & $202(36.7)$ \\
\hline Friends / relatives influences & $152(27.6)$ \\
\hline Easy access to over the counter products & 20 (3.6) \\
\hline Influence through media/ advertisements & $3(0.5)$ \\
\hline \multicolumn{2}{|l|}{ Reasons for females to take medical advice for $\mathrm{VD}^{\mu}$} \\
\hline The condition has got worse & $481(87.5)$ \\
\hline Fear of serious disease & $370(67.3)$ \\
\hline Vaginal discharge is intolerable & $305(55.5)$ \\
\hline Fear of sexually transmitted infection & $108(19.6)$ \\
\hline Previous good experience with medical treatments & $27(4.9)$ \\
\hline \multicolumn{2}{|l|}{ The reasons for females not taking medical advice for $\mathrm{VD}^{\mu}$} \\
\hline Feeling difficulty in discussing with male doctor & $481(87.5)$ \\
\hline Less knowledgeable about vaginal discharge & $336(61.1)$ \\
\hline Considering vaginal discharge as normal & $284(51.6)$ \\
\hline Afraid of internal examination because of being unmarried & $160(29.1)$ \\
\hline Busy with household activities and ignore it & $124(22.5)$ \\
\hline Cultural view of vaginal discharge & $55(10.0)$ \\
\hline It relieves with the home remedies & $31 \quad(5.6)$ \\
\hline
\end{tabular}

${ }^{\mu}$ Multiple responses were allowed. VD: vaginal discharge 